\title{
Complex heat transfer at directed crystallization of semitransparent materials
}

\author{
V.I.Deshko, A.Ya.Karvatskii, A.M.Kudin ", I.V. Lokhmanets \\ Heat Engineering Dept., National Technical University "Kiev Polytechnic \\ Institute", 37 Peremogy Ave., 03056 Kiev, Ukraine \\ "Institute for Scintillation Materials, STC "Institute for Single Crystals", National \\ Academy of Sciences of Ukraine, 60 Lenin Ave., 61001 Kharkiv, Ukraine
}

Received October 25, 2013

\begin{abstract}
The sensibility of thermal regimes at crystal-melt system to inner or outer parameters was studied for semitransparent media by the numerical simulation of complex heat transfer. A model of radiation-convective and radiation-conductive heat transfer was developed. Advanced features of the model, such as dynamic evolution of interface, were realized by implementation of user-defined functions. The $2 \mathrm{D}$ axisymmetric model is limited geometrically to the cylindrical crystal-melt system since heat regimes and temperature gradients in the area near crystallization front are the most important. Combined effect of radiation, convective and conductive heat transfer mechanisms on the formation of temperature fields and heat flows, position and shape of the crystallization front and distribution of the temperature gradients in the crystal-melt system have been examined for the oxide and alkali-halide classes of semitransparent materials at different growth conditions, considering selectivity of their absorption. Analysis of the results allowed developing the recommendations for approximation of the effects of radiation and convection heat transfer and their interaction. This allows justification of several possible simplifying approaches at development of the numerical models of crystal growth furnaces, including on-line models for operative control of the growth process.
\end{abstract}

C помощью численного моделирования сложного теплообмена изучалась чувствительность тепловых режимов системы кристалл-расплав $\kappa$ внутренним и внешним параметрам для полупрозрачных материалов. Разработаны модели радиационно-конвективного и радиационно-кондуктивного теплообмена. Такие особенности моделей, как динамическая эволюция межфазной границы, реализованы с помощью динамической сетки. Учитывая, что тепловые режимы и температурные градиенты в области фронта кристаллизации являются наиболее важными, геометрия осесимметричной $2 \mathrm{D}$ модели ограничена цилиндрической системой кристалл-расплав. Совместное действие радиации, конвективного и кондуктивного теплообмена на формирование температурных полей и тепловых потоков, положение и форму фронта кристаллизации, распределение температурных градиентов в системе кристалл-расплав исследованы для двух классов полупрозрачных материалов (оксидных и щелочно-галоидных) при различных условиях роста с учетом селективности их поглощения. Показано, что есть несколько возможностей упрощения подходов к разработке численных моделей тепловых условий роста кристаллов и кристаллизационного оборудования, в том числе для оперативного контроля процесса роста. Разработаны рекомендации для приближенного описания әффектов радиационного и конвективного теплообмена и их взаимодействия.

Складний теплообмін при направленій кристалізацї̈ напівпрозорих матеріалів. В.І. Дешко, А.Я. Карвацький, О.М. Кудін, Ю.В. Лохманець

За допомогою числового моделювання складного теплообміну вивчалася чутливість теплових режимів системи напівпрозорих матеріалів кристал-розплав до внутрішніх $\mathrm{i}$ 
зовнішніх параметрів. Розроблено моделі радіаційно-конвективного та радіаційно- кондуктивного теплообміну. Такі особливості моделей, як динамічна еволюція міжфазної границі, реалізовані за допомогою динамічної сітки. Враховуючи, що теплові режими i температурні градієнти в області фронту кристалізації є найбільш важливими, геометрія осесиметричної 2D моделі обмежена циліндричною системою кристал-розплав. Комбіновану дію випромінювання, конвективного і кондуктивного теплообміну на формування температурних полів і теплових потоків, розташування і форму фронту кристалізації, розподіл температурних градієнтів у системі кристал-розплав досліджено для оксидних та лужно-галоїдних класів напівпрозорих матеріалів при різних умовах росту, враховуючи селективність їх поглинання. Показано, що існує кілька можливостей для спрощення підходів до розробки числових моделей теплового стану росту кристалів і кристалізаційного обладнання, в тому числі для оперативного контролю процесу росту. Розроблено рекомендації щодо наближеного опису ефектів радіаційного і конвективного теплообміну та їх взаємодії.

\section{Introduction}

Dielectric single crystals have wide application in production of various devices used in science, industry, medicine, security systems, etc. The quality of single crystals obtained by directed growth from melt depends greatly on thermal parameters during growth process. Therefore, study of heat transfer processes occurring at directed crystallization of semitransparent materials from the melt is of urgent importance for manufacturing of high-quality single crystals. Uniformity and smoothness of thermal parameters, such as temperature fields (T-fields) and heat fluxes are required to minimize lattice imperfection.

As a result of increasing demand for bigsized high-quality crystals in electronic and optical industry, the advancement in their manufacturing requires new research techniques. Numerical simulation provides extensive and often irreplaceable opportunities for such studies, since direct intervention into the process in order to obtain experimental data causes the thermal balance changes. A large number of physical phenomena at directed phase-change process of the semitransparent selectively absorbing materials require considerable simplification of suitable numerical models of such systems, particularly those intended for realtime maintenance and control of the crystalgrowth processes. However, the possible effect of each assumption on accuracy of the results obtained from the model must be evaluated. Thereby the assumption usage must be justified, and the result obtained with simplified approach can be corrected (specified) if an influence of the simplifying approach is known.

There are a number of numerical models devoted to semitransparent crystals growth [1,2]. Earlier papers such as by Abrams and Viskanta [3] and Viskanta and Anderson [4], Xiao and Derby [5] have shown the dominating role of radiation heat transfer on the heat regimes near crystallization front in such systems. Radiation heat flow increases temperature gradient in the melt near interface and, as a result, increases stability of the crystallization process. Numerical investigations of influence of radiation-conductive heat transfer on the heat regimes at oxide crystal growth (where crystal is semitransparent to the infrared radiation while the melt phase is opaque) were presented in much more limited number of papers, particularly in the papers of Yeckel and Derby [6], Yuferev et al. [7]. Hayashi et al. [8] considered the optically thin crystals only. Due to complexity of radiation calculation in the semitransparent medium, Galazka and Wilke [9] and Voigt et al. [10] considered the radiation heat transfer only between surfaces of the crystal-melt system and crucible. Other papers, e.g. Evstratov et al. [11], Kalaev et al. [12] deal with convection heat transfer under the growth process in entirely opaque systems. After all, selectivity of optical properties may take place both in the crystal and in the melt, caused by selective properties of the material itself or by absorptive impurities for the scintillating crystals, that reported by e.g. Kolesnikov et al. [13]. Most of the models consider the radiation heat transfer in the gray assumption; however Lin and Dold [14] have shown that such assumption may cause overstating of the value of calculated sample's temperature by $10 \mathrm{~K}$.

This brief overview shows that the existing numerical models of crystallization furnaces do not usually take into account the complexity of the radiation-convection interaction, occurring under growth of the semitransparent materials with selective optical properties. However, it is possible to use a geometrically limited quasy-steady numerical model to examine this interaction, 
to evaluate the influence of inner and outer conditions and to estimate the acceptability of certain assumptions for a specific simulation of the crystal growth furnace.

According to Yeckel and Derby [15], the computational time for full-scale transient simulation of entire furnace including all important physical phenomena remains unacceptable. Therefore, a number of partial numerical models of the same process may be used depending on the purpose of calculations. For real-time control of the growth process, simpler and faster models provide supplemental data to improve thermal parameters of the process. To explore the complex interaction of heat transfer mechanisms (along with other physical phenomena) on temperature distribution, heat flows and shape of interface, more detailed models are required. Such models, however, may consider the most important domain only, e.g. the crystal-melt system. Finally, global models of entire crystallization furnace (but with simplified handling of the certain domains) are suitable for comprehensive analysis of the thermal regimes in the unit as it shown by Deshko et al. [16].

In this work, a series of calculations was conducted on numerical models of the crystal-melt system for the purpose to ascertain the sensitivity of the heat regimes on a number of factors, corresponding to different growth methods and growing materials. In majority of the cases, 2D axisymmetric models are the most appropriate for geometries of the crystal growth furnaces, however a certain useful observation can be obtained also with the fast 1D models (see, for example Deshko et al. [17]), e.g. influence of absorptivity and height of the crystal and melt on required dynamic of temperature change at control heater during the growth process.

The purpose of such approach is the justification of simplifying approaches at development of the numerical models. As a result, this allows developing the fast numerical models of the real crystallization furnaces with their complex geometry, considering only the most important physical phenomena while minimizing deviations of the results caused by simplifications made. Such global models can be used for realtime optimization of the thermal regimes of the growth process, e.g. updating of the control parameters (temperature of control heater) by implementation of simulated data into the furnace operation.

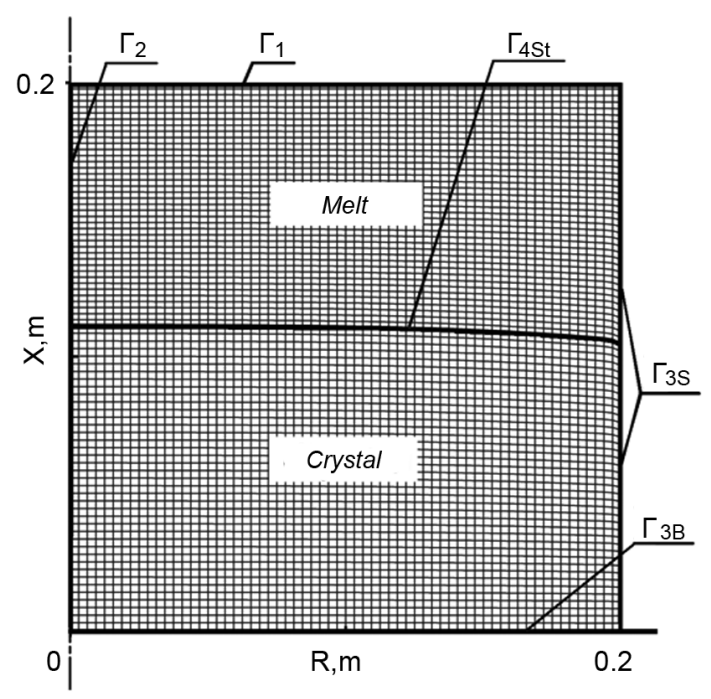

Fig. 1. Geometry, boundary conditions and mesh of the computational domain: $\Gamma_{1}-$ temperature (Dirichlet) boundary conditions; $\Gamma_{2}$ - symmetry axis (the Neumann boundary condition); $\Gamma_{3 \mathrm{~S}}-$ and $\Gamma_{3 \mathrm{~B}}-$ convection boundary conditions on the side and bottom boundary, respectively; $\Gamma_{4 \mathrm{St}}-$ the Stefan condition.

\section{Problem formulation, boundary conditions and meshing}

To investigate an influence of material properties and operating conditions on thermal conditions in the crystal-melt system, a numerical model of radiation-convective (in the melt) and radiation-conductive (in the crystal) heat transfer was developed in Ansys Fluent, a commercially available CFD solver based on the finite volume method [18]. The geometry and boundary conditions of the problem are given in Fig. 1. Single crystals are grown as cylindrical-shaped, and the most elements of crystallization furnaces are axisymmetrical. Therefore the model developed is two-dimensional axisymmetric and the both crystal and melt are cylinders of the same radius, which corresponds well to majority of the growth methods. Gravitational vector is parallel to symmetry axis and is directed downwards in the basic case, so the system is upper-heated. This corresponds to the Axial Heating Process (AHP) crystal growth method, described by Bykova et al. [19]. The direction of gravitational vector may be reversed, which corresponds to bottom-heated growth methods, e.g. the Czochralski growth. Linear sizes of the domain may be changed to 
simulate different stages of the growth process.

Mathematical formulation includes energy, momentum and continuity equations, with source term $E(\mathbf{X})$ in energy equation corresponding to the internal heat rate due to absorption and emission in an elemental volume of the semitransparent media:

$$
\begin{gathered}
\frac{\partial}{\partial \tau}(\rho h)+\nabla \cdot(\rho \boldsymbol{V h})=\nabla \cdot(\lambda \nabla T)+E(\boldsymbol{X}), \\
E(\boldsymbol{X})=\int_{v=0}^{\infty} k_{v}\left[4 \pi n_{v}^{2} I_{0 v}-\int_{\Omega=4 \pi} I_{v}(\Omega) d \Omega\right] d v, \\
\frac{\partial \rho \boldsymbol{V}}{\partial \tau}+(\rho \boldsymbol{V} \cdot \nabla) \boldsymbol{V}=-\nabla p+\nabla \cdot[\mu(\nabla \boldsymbol{V})]+\rho \boldsymbol{g}, \\
\frac{\partial \rho}{\partial \tau}+\nabla \cdot(\rho \boldsymbol{V})=0,
\end{gathered}
$$

where $h=\int_{T_{R E F}}^{T} c_{p} d T$ is sensible enthalpy, $I_{0 v}$ is black body radiation intensity given by the Planck function, $I_{v}(\Omega)$ - spectral radiation intensity of frequency $v$ in direction $\mathbf{s}$ of solid angle $\Omega, k_{v}, n_{v}-$ spectral absorption coefficient and spectral refractive index, respectively. Material properties, such as heat conductivity, density and viscosity, are the functions of temperature: $\lambda=f_{\lambda}(T), \rho=f_{\rho}(T)$, $\mu=f_{\mu}(T)$.

Radiation field in absorbing and emitting medium is given by the spectral radiation intensity $I_{v}(\mathbf{X}, \mathbf{s})$, which is described by the radiation transfer equation (RTE):

$$
\frac{d I_{v}(\boldsymbol{X}, \boldsymbol{s})}{d s}+k_{v} I_{v}(\boldsymbol{X}, \boldsymbol{s})=k_{v} n_{v}^{2} I_{0 v} .
$$

Initial conditions at $\tau=0$ are the following:

$$
\left\{\begin{array}{l}
T(X)=T_{0} \\
\boldsymbol{V}(X)=0
\end{array}\right.
$$

The initial shape of the interface is flat, providing equal sizes of the crystal and melt zones:

$$
\left.\Gamma_{4 S t}\right|_{\tau=0}=f(\boldsymbol{X}) .
$$

Melt butt is defined with the temperature boundary condition. The bottom and side temperature boundary conditions are convective, representing combined radiation-convective heat contact with the con- struction elements of the furnace such as crucible or side heater, and environment (bottom):

$$
\boldsymbol{n} \cdot(-\lambda(T) \nabla T)=\alpha_{e f f}\left(T-T_{\infty}\right) .
$$

The thermal conditions of the crystal growth process can be regulated by side heater, e.g. by changing its power, position, screening and distance to the crystal-melt system. All these changes may be represented by varying the side boundary conditions of the model.

The domain includes the internal semitransparent boundary - namely crystallization front (interface) with the Stefan boundary condition applied, which includes radiation heat flow qr on the semitransparent interface:

$$
\left\{\begin{array}{l}
\left.T\right|_{S}=\left.T\right|_{L}=T_{m} \\
\boldsymbol{n} \cdot(-\lambda(T) \nabla T)-\boldsymbol{n} \cdot \boldsymbol{q}_{\tau}=\rho_{S} L_{f}\left(\boldsymbol{n} \cdot \boldsymbol{V}_{\boldsymbol{S}-\boldsymbol{L}}\right)
\end{array},\right.
$$

where $T_{m}$ is equilibrium crystallization temperature, $L_{f}$ is specific heat of crystallization, $\rho_{S}$ is crystal density, and $\mathbf{V}_{S-L}$ is interface velocity vector.

The symmetry boundary conditions are applied on the symmetry axis:

$$
\begin{aligned}
& \boldsymbol{n} \cdot \nabla T=0, \\
& \boldsymbol{n} \cdot \nabla \boldsymbol{V}=\mathbf{0} .
\end{aligned}
$$

The no-slip boundary condition for velocity is applied to the melt butt, melt side surface and crystal-melt interface:

$$
\boldsymbol{V}=\mathbf{0} \text {. }
$$

Radiation calculations assume the isotropy of the medium and diffusive reflections on the boundaries. Basic case considers the gray medium. The previous experiments have shown that convection is suppressed in the upper-heated system and no significant turbulence is observed, so the laminar model was used for such conditions. Due to the very low crystallization rate (typical magnitude of crystal growth is $1 \mathrm{~mm} / \mathrm{h}$ ) the steady assumption was used.

The domain was divided by the computational mesh on quadrilateral-sectioned toroidal elements. The optimal mesh side was chosen by comparative calculations on the meshes consisting of 1280,5120 and 20480 elements to provide a balance between the solution time and accuracy. The mesh of 5120 elements, equally for each phase: $64(R) \cdot(40 \mathrm{cr}+40 \mathrm{~m})(X)$ proved to be sufficient for the most cases. However, in several calculated cases with sharp tempera- 
Table 1. Properties of BGO and CsI

\begin{tabular}{||c|c|c|c|c|}
\hline Property & BGO crystal & BGO melt & Csl crystal & Csl melt \\
\hline Heat conductivity, $\mathrm{W} / \mathrm{m} \cdot \mathrm{K})$ & 1.20 & 0.14 & $\lambda_{c r}(T)$ & 0.1 (eff. 30) \\
Heat capacity, J/(kg.K) & 334.5 & 410.0 & 201 & 274 \\
Density, $\mathrm{kg} / \mathrm{m}^{3}$ & 7090 & $6975-0.25 T$ & 4510 & $\rho_{m}(T)$ \\
Refraction index & 2.1 & 1.9 & 1.7 & 1.5 \\
Absorption coefficient, $\mathrm{m}^{-1}$ & 3.0 & $>15000$ & 1.0 & 1.0 \\
Crystallization temperature, K & - & 1323 & - & 894 \\
Viscosity, $\mathrm{kg} /(\mathrm{m} \cdot \mathrm{s})$ & - & 0.05406 & - & $\mu_{m}(T)$ \\
\hline
\end{tabular}

$\lambda_{c r}(T)=1.9119-0.003497 \cdot T+2 \cdot 10^{-6} \cdot T^{2}$

$\rho_{m}(T)=4241-1.1834 \cdot T$

$\mu_{m}(T)=0.041821-1.01156 \cdot 10^{-4} \cdot T+8.4957 \cdot 10^{-8}-\mathrm{T}^{2}$

ture gradients, the local refining of the mesh was employed.

Two classes of semitransparent materials were modeled: oxide crystals represented by bismuth germanate $\mathrm{Bi}_{4} \mathrm{Ge}_{3} \mathrm{O}_{12}$ (BGO) and alkali halides represented by cesium iodide Csl. The former class is typically characterized by almost opaque melt while the latter implies the both phases being semitransparent. The properties of these materials used for basic calculations are presented in Table 1. In order to include the buoyancy and more accurate treatment, the melts densities as well as some other properties were set as linear or polynomial functions of temperature (in $\mathrm{K}$ ) basing on the available reference data.

The outer temperature boundary conditions are set as follows: $\Gamma_{1}-$ temperature $T=$ $1450 \mathrm{~K}$, opaque with emissivity $\varepsilon=1 ; \Gamma_{3 S}-$ convective boundary condition with heat transfer coefficient $\alpha=100 \mathrm{~W} /\left(\mathrm{m}^{2} \cdot \mathrm{K}\right)$ and free stream temperature varying linearly or stepwise from $1300 \mathrm{~K}$ at $X=0$ to $1450 \mathrm{~K}$ at $X=0.2$, opaque with emissivity $\varepsilon=0.5$; $\Gamma_{3 B}-$ convective boundary condition with $\alpha=10 \mathrm{~W} /\left(\mathrm{m}^{2} \cdot \mathrm{K}\right)$ and free stream temperature $323 \mathrm{~K}$, semitransparent with emissivity internal/external $\varepsilon=0.1579 / 0.6965$.

\section{Numerical modelling}

The system was modeled using the Ansys Fluent CFD software, which employs the finite volume method (see Versteeg and Malalasekera [20], for example) for the main governing equations (momentum and energy). Heat transfer by radiation in a selectively absorbing and emitting medium is calculated using the Discrete Ordinates (DO) method [18].
Uncoupled implementation of the DO method to energy equation was used, providing better convergence in the most cases with modest optical thickness of the crystalmelt system. The equations for the energy and radiation intensities are solved one by one, assuming prevailing values for other variables. Radiation is calculated every 2 flow iterations.

The DO radiation model solves the radiation transfer equation for a finite number of discrete solid angles, each associated with a vector direction $\mathrm{s}$ fixed in the global Cartesian system. The DO model transforms the RTE into a transport equation for radiation intensity in the spatial Cartesian coordinates and solves it for as many transport equations as there are directions (s). The solution method is identical to the one used for the fluid flow and energy equations. The non-gray DO implementation divides the radiation spectrum into up to nine random wavelength bands with the RTE integrated over each wavelength interval. Such implementation is however limited by the fact that behavior in each band is assumed as gray. The total intensity at given position $\mathbf{X}$ in each direction $\mathbf{s}$ is obtained by the summation of the radiation intensities in each band.

The fineness of the angular discretization is controlled by a number of divisions of each octant of the angular space $4 \pi$ in polar and azimuthal directions, $N_{\theta} \cdot N_{\varphi}$. In two-dimensional calculations, only four octants are solved due to the symmetry, making a total of $4 N_{\theta} \cdot N_{\varphi}$ directions in all. In the case of the non-gray model, $4 N_{\theta} \cdot N_{\varphi}$ equations are solved for each band. Additional difficulty is that control volume faces do not in general align with the global an- 
gular discretization, leading to the problem of control angle overhang, described by Murthy and Mathur [21], and accuracy reduction. To deal with this problem, each overhanging control angle is divided into $N_{\theta p} \cdot N_{\varphi p}$ pixels. While the standard values for angular discretization and pixel resolution are $2 \times 2$ and $1 \times 1$ respectively, the values $5 \times 5$ and $3 \times 3$ proved to be required for the present model because of the decisive role of radiation heat transfer. These values, however, affect greatly performance of the numerical model.

Since natural convection is modeled inside a closed melt domain, the solution depends on mass inside the domain. Since this mass will not be known unless the density is known, it is required to use unsteady solver or the Boussinesq density model [18]. Considering significant (tens of degrees) temperature differences in the melt domain, the transient calculations were performed, though with steady boundary conditions. An unsteady pressure-based segregated solver with implicit formulation is used for solving the discretized energy end momentum equations. First order method is used for unsteady terms. The algorithm used is SIMPLE with fitted under-relaxation factors to enhance the convergence. Fluent uses segregated algorithms for solving the governing equations. Each one is decoupled (segregated) from other equations. Since the discretized equations need to be stored in the memory only one at a time, the memory requirements are lower, but convergence is relatively slow.

The second order upwind scheme is used for convective terms, energy and the DO equations, providing improved accuracy. The absolute convergence criterion for continuity and velocity components was set equal to $10^{-3}$ and value $10^{-7}$ was used for the energy and DO equations because of its significant impact on the calculated temperature fields.

Several calculations were conducted with bottom heating of the crystal-melt system, i.e. with the melt domain under the crystal. Such conditions are favorable for development of the natural convection in the melt, therefore possible turbulence effects must be considered. For such cases modified $k-\varepsilon$ model, namely the RNG proposed by Orszag et al. [22] was used. The RNG $k-\varepsilon$ model has several refinements, making it more reliable and accurate for the wider class of flows, including swirling and the lowReynolds number flows. Comparative calcu- lations showed better convergence for considered problem with the highly viscous melt. The standard values for the RNG $k-\varepsilon$ model constants were applied.

The numerical model has been validated by comparison with several known analytical and numerical solutions for conductive and radiation-conductive problems. Particularly, the one-dimensional Stefan problem solved by Abrams and Viskanta [3] was reproduced with mean-square deviation about $0.5-2 \%$.

An important feature of the developed numerical model is the ability to dynamically change position and shape of the crystal-melt interface according to current temperature field in the system. Although the Fluent software includes the solidificationmelting model, it considers solid-liquid domain as a single (actually, being entirely liquid). Instead of tracking the liquid-solid front explicitly, an enthalpy-porosity formulation is employed [18]. Being appropriate for modelling the phase-change processes in opaque medium such as metals, it is unsuitable for considered problem with the semitransparent interface and different optical properties (refractivity and absorptivity) of solid and liquid phases.

Therefore a complex user-defined function (UDF) of dynamic mesh motion was developed and implemented into the model. The steps executed by the UDF are the following:

1. Each time being called (each specified number of iteration, time step or on demand), the UDF receives and stores into arrays current temperature field for (1) current position of the crystal-melt interface, (2) the side boundaries and (3) all cells in the crystal-melt domain.

2. The crystal-melt area is divided into columns of 1 cell in width (each one is stretched vertically through the crystal and melt domains). For each column, as well as for the side boundaries, a new interface position is determined as a coordinate where given crystallization temperature is achieved. The function of temperature on coordinate is assumed to be monotonic.

3. Smoothing of determined in Step 2 new interface shape, if needed. Due to roughness of the calculated temperature field caused by convection, the smoothing may be implemented by several techniques, including 3-, 5-, and 7-point linear filtering.

4. Computational grid is deformed column-by-column with specified under- or 

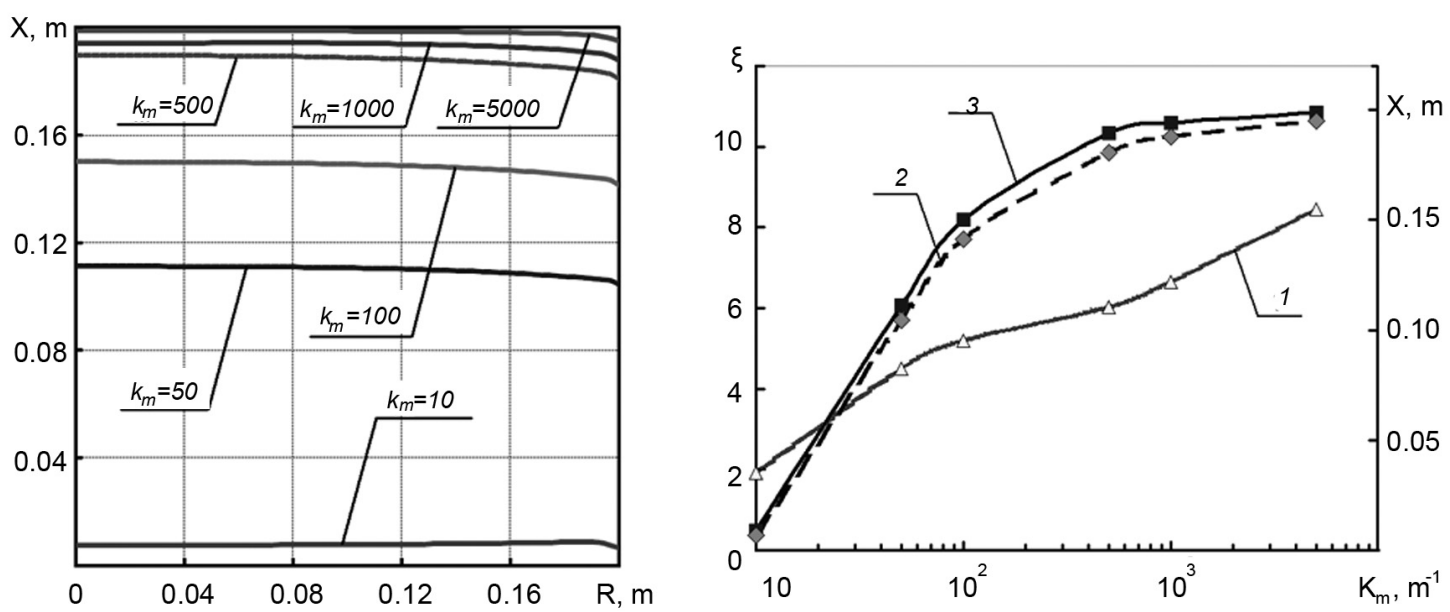

Fig. 2. Dependence of the interface shape (left) and position (right) on the melt absorptivity: 1 optical thickness of the melt layer $\xi ; 2-$ interface position on the side surface; 3 - interface position on the symmetry axis.

over-relaxation factor. Thus the interface is moved towards current isotherm of the crystallization temperature, each $R$-coordinate is moved independently, making possible to change the shape of the interface as well as the position. The cells in the crystal and melt domains are squeezed or stretched accordingly.

Thus the technique allows dynamic tracing of the interface position and shape according to the current thermal conditions. Additional simple UDF is used to define non-uniform temperature distribution for the boundary condition on the side surface.

\section{Results and discusion}

The case with upper heating, resembling growth conditions of the AHP method was used as a basis for calculation series with variable absorption coefficient of the melt. The goal is to analyze an impact of the melt's absorptivity on distribution of T-fields and the interface position during growth process. Such conditions correspond to different types of the grown materials. The change of absorption may also be caused by introduction of additive agents (dopes) to furnace charge.

Basing on the material with BGO properties (except absorption coefficients), melt absorption coefficient $k_{m}$ was varied from 10 to $5000 \mathrm{~m}^{-1}$ while crystal absorption coefficient $k_{c r}$ was fixed with value of $10 \mathrm{~m}^{-1}$. Calculations results indicated a moderate change of the radius-averaged melt optical thickness comparing to much more considerable change of the control factor $k_{m}$

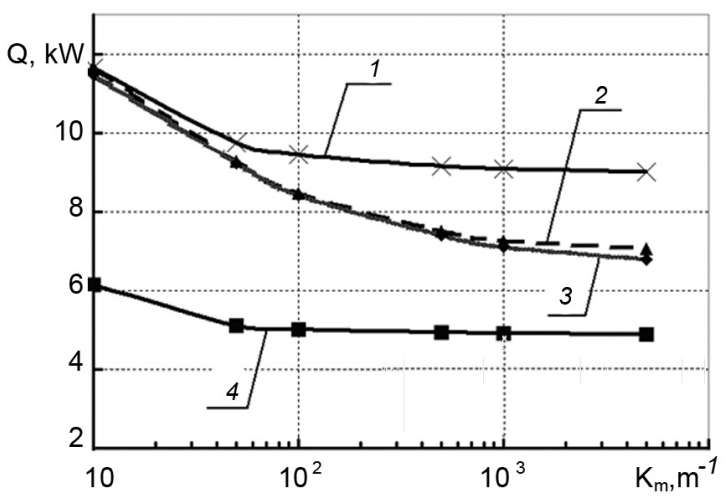

Fig. 3. Dependences of the heat transfer rates on the melt absorptivity 1 - total heat flow on the crystal butt; 2 - total heat flow interface; 3 - radiation heat flow on the interface; 4 - radiation heat flow on the crystal butt.

(Fig. 2). This revealed stabilization of the melt optical thickness $\xi$ at absorptivity change during crystallization process leads to conservation of considerable radiation heat flows even through nearly opaque (5000 $\mathrm{m}^{-1}$ ) melt (Fig. 3). Radiation heat transfer plays decisive role in the heat transfer at growth of the optically transparent crystals. This directly influences convection flows in the melt. Reduction of the melt thickness causes significant weakening of the convective flows (e.g. two flow contours degenerate into the single contour). Temperature gradients in the melt increase inversely to thickness of its layer. The value of the Rayleigh number for this configuration lies in the range from $1.6 \cdot 10^{5}$ for thin melt layer to $8 \cdot 10^{8}$ for almost entirely 


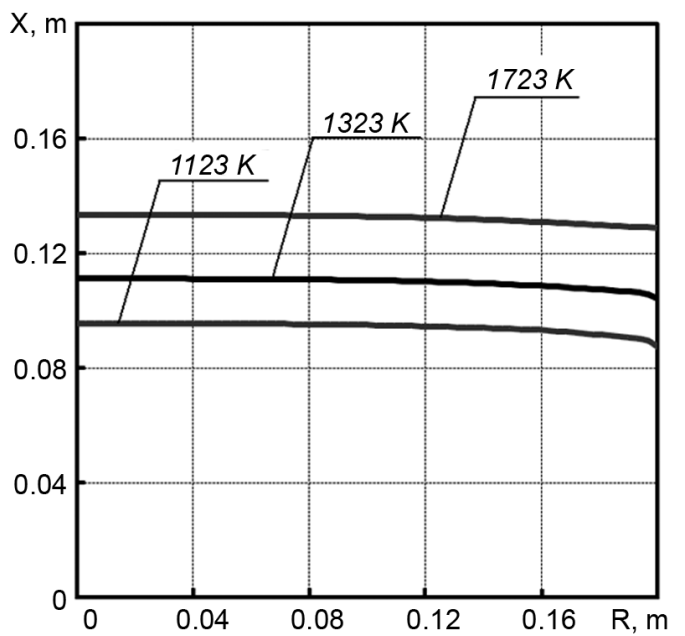

Fig. 4. Influence of the temperature level on the interface position.

melted domain. This value, however, does not take into account the direction of the heat flow (upper or lower-heated system).

In the conditions of radiation-convective heat transfer in upper-heated system the role of convection is negligible. At nearly opaque melt radiation heat flow in the system is formed near interface, heat sink from the interface is maximal, and the interface displaces to the upper hot boundary. A characteristic feature of this case is a combination of high temperature gradients in the melt and low temperature gradients in the crystal.

An additional investigation of the system's radiation properties was conducted by several comparative calculations. Opacity of the crystallization front causes relatively small effect on the T-fields and its own position. However, semitransparency of the crystal butt (distinctive feature of the AHP growth method, providing options for radiation control) causes a significant decrease in the melt thickness and weakening of convective flows in it. In the absence of radiation (fully opaque system, such as semiconductors or metals) the significant enhancement of convection is observed. It is caused by the sharp rise of radial component of the temperature gradient near the lateral surface.

Additional effects here are the reduction of the axial gradient in the melt and its increase in the crystal. Finally, instability of the T-fields in the system is observed, which is expressed by unstable (oscillating within process of numerical solution) position and shape of the interface. Therefore, presence of the powerful radiation heat flow

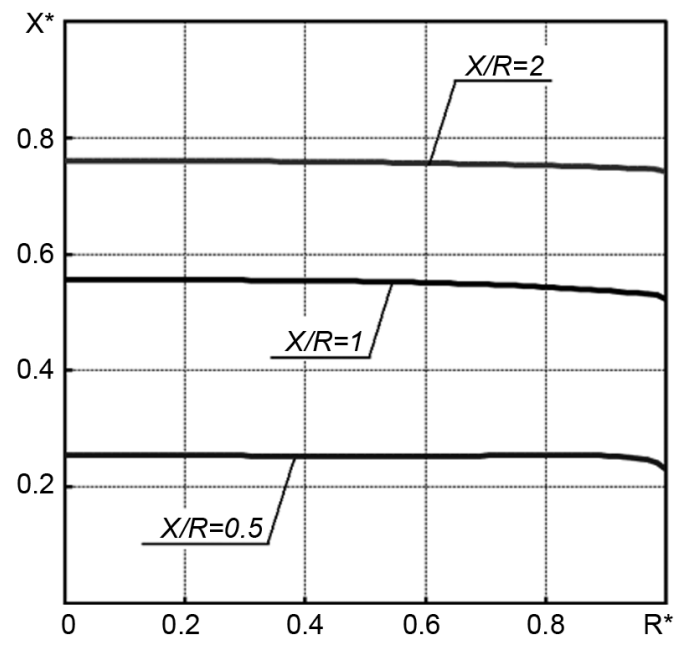

Fig. 5. Relative interface position for different stages of the process.

has a significant stabilizing effect on the T-fields and on the interface shape, provides an opportunity for sustainable process of the directional crystallization as well as additional options for control of the growth process.

A temperature level in the installation greatly affects the value of the radiation heat flows. To obtain quantitative evaluation of such changes (due to higher- or less-melting material grown), additional calculations were conducted with crystallization temperature, increased by $400 \mathrm{~K}$ and also with decreased by $200 \mathrm{~K}$. All temperatures in the boundary conditions were changed accordingly. For example, increased temperature level sharply increases the system heat load (2.5 times - the total heat flows, 3 times - the radiation heat flows) and substantial reduction of the melt layer (Fig. 4), due to stronger radiation heat sink. Influence of the temperatures level and its drop across the system on convective flow is also observed, but not so strong.

The experiment with variation of overall height of the crystal-melt system represents different stages of the growth process in which the crystal is pulled from the melt of constant thickness. The results have shown that during the crystal pulling process the axial heat flows slowly decrease. Within the fixed boundary conditions on the system butts, the melt thickness (Fig. 5) and convection intensity increase substantially. Therefore, to maintain the constant melt layer during the process, additional control of outer conditions is required. The determination of required dynamic of their 

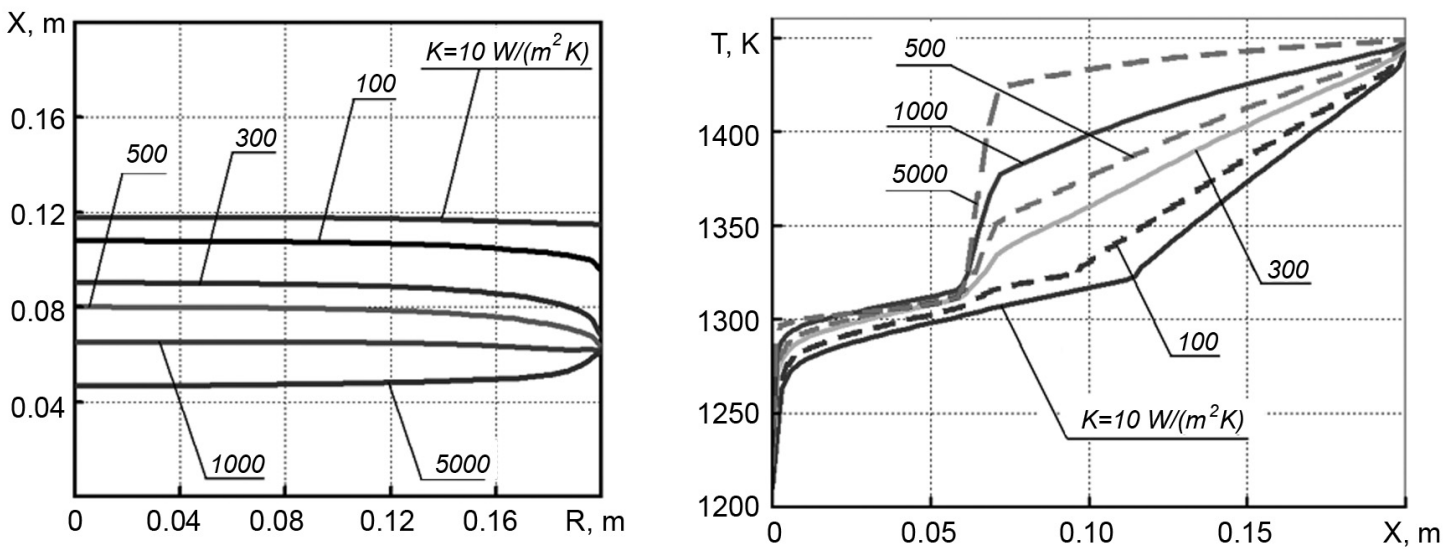

Fig. 6. Influence of an effective heat transfer coefficient $K$ on the interface position (left) and temperature distribution along the side surface of the crystal-melt system (right).
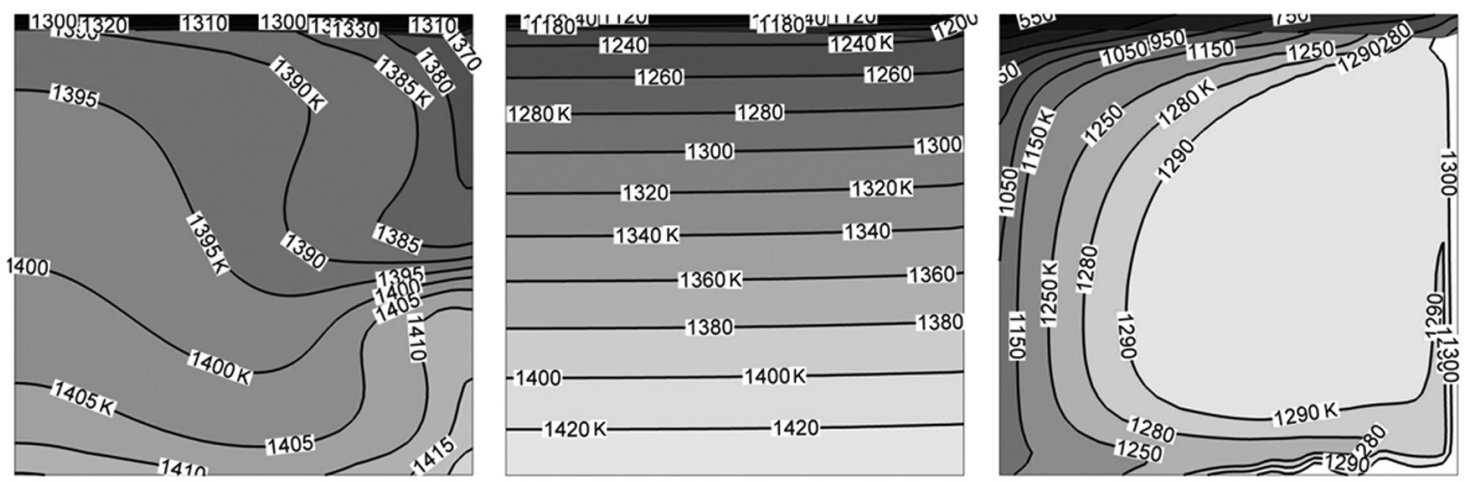

Fig. 7. Temperature fields in the melt with applied radiation-convective (left), radiation-conductive (middle), and convective (right) heat transfer mechanism for the bottom heating case.

change for each case is another application of the present model. The interface position, represented in Fig. 5, is given in dimensionless coordinates - height $X^{*}$ and radius $R^{*}$, while height of the system $X$ was varied from $0.1 \mathrm{~m}(X / R=0.5)$ to $0.4 \mathrm{~m}$ $(X / R=2)$, showing the initial, intermediate and final stages of the growth process.

The temperature fields in the crystalmelt systems often require dynamic corrections. One of important approaches is a control of lateral heaters. Such method of control in given numerical model is represented by change of the side boundary conditions: both heat transfer coefficient and free stream temperature. Value of the heat transfer coefficient is effective and reflects both radiation and convective heat transfer from the lateral heater. Increase of this effective coefficient means the lower gap or removal of reflective screen between the heater and side surface of the crystal-melt system or crucible.

Free stream temperature reflects the vertical temperature profile of lateral heaters (determined by the growth method and construction of the furnace and regulated usually by their electrical power). Its change means movement of the crystal-melt system within the temperature profile created by the heaters. Influence of the temperature conditions on the side boundary is examined by the both approaches: 1) comparison of linear and stepwise profiles of the vertical distribution of the free stream temperature and 2) variations in the heat transfer coefficient $K$ of the side surface from $10 \mathrm{~W} /\left(\mathrm{m}^{2} \cdot \mathrm{K}\right)$ to $5000 \mathrm{~W} /\left(\mathrm{m}^{2} \cdot \mathrm{K}\right)$.

The numerical investigation shows that the increase of $K$ causes a significant growth of the melt thickness (Fig. 6), as well as enhances convection in the melt. Another effect is an increasing role of the lateral heat flows. For instance, the lateral heat flows become comparable to the axial ones at $K=5000 \mathrm{~W} /\left(\mathrm{m}^{2} \cdot \mathrm{K}\right)$. The calculations have shown that the control via side surface of the crystal-melt system allows modifying the thermal conditions and position of the interface in a wide range. 
Table 2. Heat transfer rates in the crystal-melt system with different heat transfer mechanisms active

\begin{tabular}{|c|c|c|c|c|c|c|}
\hline \multicolumn{2}{|c|}{ Heat transfer mechanism } & \multicolumn{2}{|c|}{ Radiation-convective } & \multirow{2}{*}{$\begin{array}{l}\text { Radiation- } \\
\text { conductive }\end{array}$} & \multicolumn{2}{|c|}{ Convective } \\
\hline & & laminar & $\mathrm{k}-\varepsilon$ & & laminar & $\mathrm{k}-\varepsilon$ \\
\hline \multirow{5}{*}{$\begin{array}{l}\text { Total heat flow } \\
\text { through the } \\
\text { boundary, W }\end{array}$} & Crystal butt & -11458 & -11948 & -8366 & -2148 & -2255 \\
\hline & Crystal-melt & 12000 & 11981 & 8250 & 1880 & 1985 \\
\hline & Melt butt & 11600 & 12370 & 7566 & 1145 & 1167 \\
\hline & Crystal side & -11 & -32 & 83 & 262 & 268 \\
\hline & Melt side & -118 & -387 & 714 & 740 & 813 \\
\hline \multirow{3}{*}{$\begin{array}{l}\text { Radiation heat } \\
\text { flow through the } \\
\text { boundary, W }\end{array}$} & Crystal butt & -6090 & -6308 & -4136 & 0 & 0 \\
\hline & Crystal-melt & 11652 & 11636 & 8024 & 0 & 0 \\
\hline & Melt butt & 11393 & 12100 & 7470 & 0 & 0 \\
\hline
\end{tabular}

In the case of lower heating (the melt is under the crystal, representing conditions of common growth methods such as the Czochralski growth), mean velocity in the melt domain increases rapidly by about 2 orders of magnitude. The temperature field, formed in the melt (Fig. 7), is sharply nonlinear in accordance with the main directions of the convective flows. Intensification of the convection leads to a significant increase in the average temperature of the system and reduce the crystal thickness. The interface shape is quite irregular and uneven due to developed convective flows. A comparison of the numerical calculations performed employing the RNG $k-\varepsilon$ model and within the laminar approximation revealed the proximity of the convective flow structures (Fig. 8) and derived heat flows at the melt boundaries (Table 2). Therefore, the laminar model remains adequate for evaluation of thermal parameters in the crystal-melt system under considered conditions even in the bottom-heated case.

The comparative calculations have shown that the laminar model usually requires less number of iterations to converge the solution, but it does not always guarantee the convergence itself, as well as stability and monotony of the obtained interface shape. This makes the laminar model more appropriate for the low-intensity convection, particularly for the cases with upper heating where convection is suppressed. To compare the effect of radiation and convection on the thermal conditions in the melt domain we consider the bottom heating case. The convection and radiation heat transfer were sequentially disabled. The resulting T-fields (Fig. 7) and heat flows in the system (Table 2) confirm the dominant role of radiation in such conditions. Also, it is clearly observed
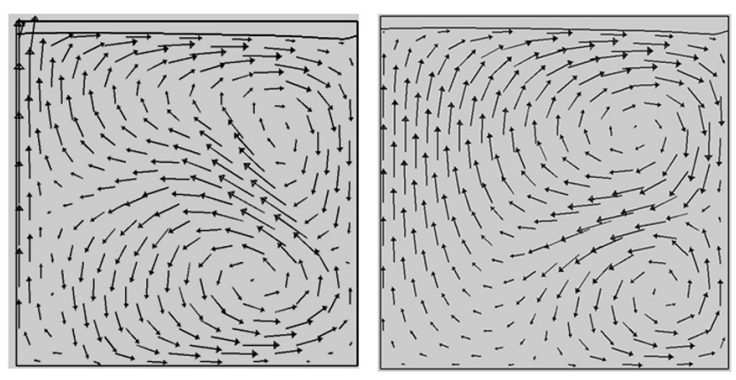

Fig. 8. Velocity vectors in the melt with bottom heating utilizing the laminar model (left) and the RNG $k-\varepsilon$ model (right).

that the strong axial radiation heat flow contributes greatly to smoothing of the temperature fields in the entire system.

The calculations for the bottom-heated case showed slower convergence; they required more efforts for solver tuning, including decrease of the under-relaxation factors. The complication caused by developed natural convection in the melt area may be avoided by the simplifying approach. Effect of the heat transfer enhancement by convection may be simulated by introducing an effective thermal conductivity, thus disabling convection in the model. Applicability of this approach was inspected by comparison of the temperature fields obtained with the real convection and effective thermal conductivity. The value of the latter $(30 \mathrm{~W} /(\mathrm{m} \cdot \mathrm{K}), 300$ time more than the real value) is chosen to provide the best fitting of the resulting T-fields and interface position. The bottom heated case of Csl growth with highly-transparent $\left(1 \mathrm{~m}^{-1}\right)$ is considered (Fig. 9).

Apparently from Fig. 7, the temperature gradients in the melt are non-uniform taking high values in the boundary layers and 

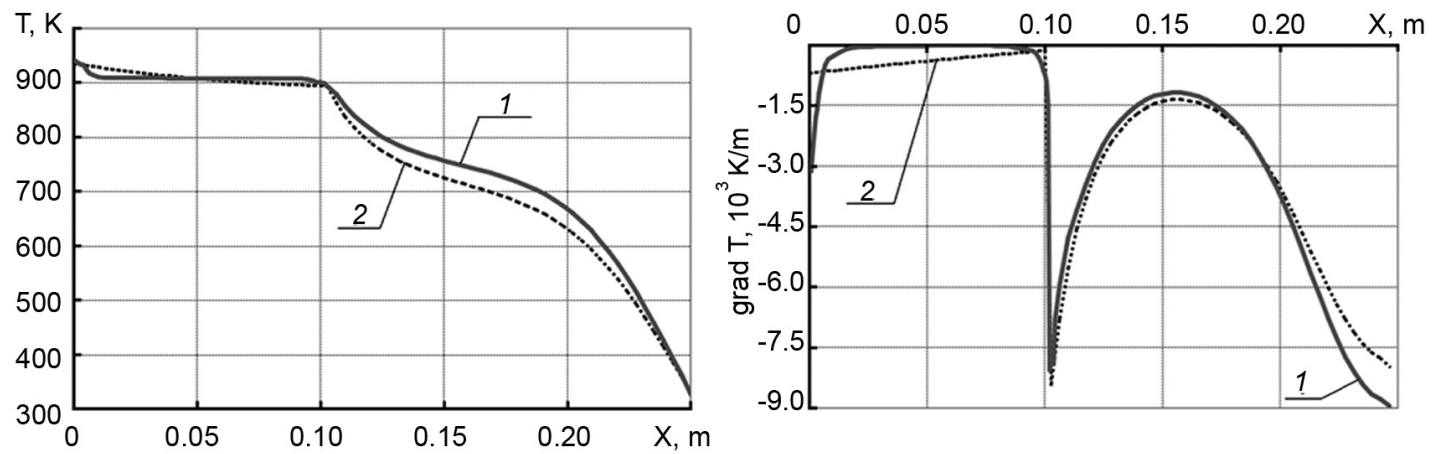

Fig. 9. Temperature distribution along the symmetry axis (left) and the corresponding temperature gradients (right). 1 - convection in the melt; 2 - effective conductivity of the melt.

being miserable in the central layer. Obviously they can not be represented adequately by the model with an effective thermal conductivity. However, in some cases the global models of entire furnace may utilize such approach, since the temperature field and heat flows for other elements of the installation are roughly conserved. The local model such as presented should be used to choose the most appropriate value of the effective melt conductivity. For the up-heated case, the effective conductivity approach is even more useful due to low intensity of convection; the effective conductivity value is only 5 times more than the real one.

Selectivity of the optical properties of the crystal and/or melt often takes place and may be caused by opacity bands in the material itself (e.g. BGO crystals) or by absorptive impurities contained in the crystal and melt (Csl doped with carbonates). As mentioned before, the current implementation of the model considers selective radiation as a combination of gray radiation in several prescribed bands. Fig. 10 illustrates stepwise approximation of absorption coefficients of the both materials used for the simulation. The goal of these calculations is the inaccuracy evaluation caused by disregarding of possible selective properties of the grown material.

Analysis of the simulation has shown that the Rosseland averaging for absorptive coefficient is not satisfactory, since it does not allow representing the real position and the interface shape. The comparative calculations of gray and selective models make possible to nearly match the T-fields for selective system using certain gray absorption coefficient. Fig. 11 shows the temperature distribution for Csl, where experimental value of the crystal and melt absorptiv-

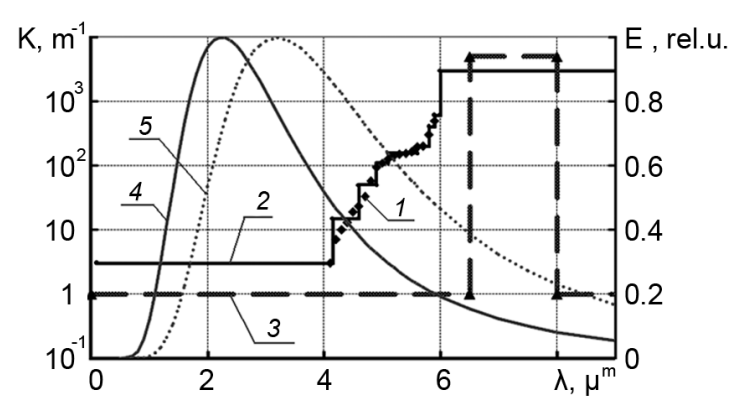

Fig. 10. Spectral absorptivity of the materials used for simulation. $1-\mathrm{BGO}$, referenced data; 2 - BGO, stepwise approximation; 3 Csl, stepwise approximation; 4,5- the Planck distribution for crystallization temperatures of BGO and CsI, respectively.

ity $k=2 \mathrm{~m}^{-1}$ is compared with the Rosseland-averaged value of $1.1 \mathrm{~m}^{-1}$. For bismuth germinate, the melt absorptivity found from the Rosseland averaging is $4.37 \mathrm{~m}^{-1}$. However, the chosen value fitting best the results of the non-gray calculation is $3 \mathrm{~m}^{-1}$. Therefore, to simplify calculations of the global heat transfer models of crystallization furnaces with selectively absorbing materials, it is reasonable to choose the appropriate value of gray absorptivity by the calculations on simplified model of the crystal-melt system.

\section{Conclusions and recommendations}

The numerical simulation of crystal growth installations allows maintaining control of the process and optimization of the thermal conditions. This results in improved productivity of the installation, reduction of its energy intensity, and quality of the single crystals. The complex numerical models of entire furnaces always represent compromise between their accuracy and 

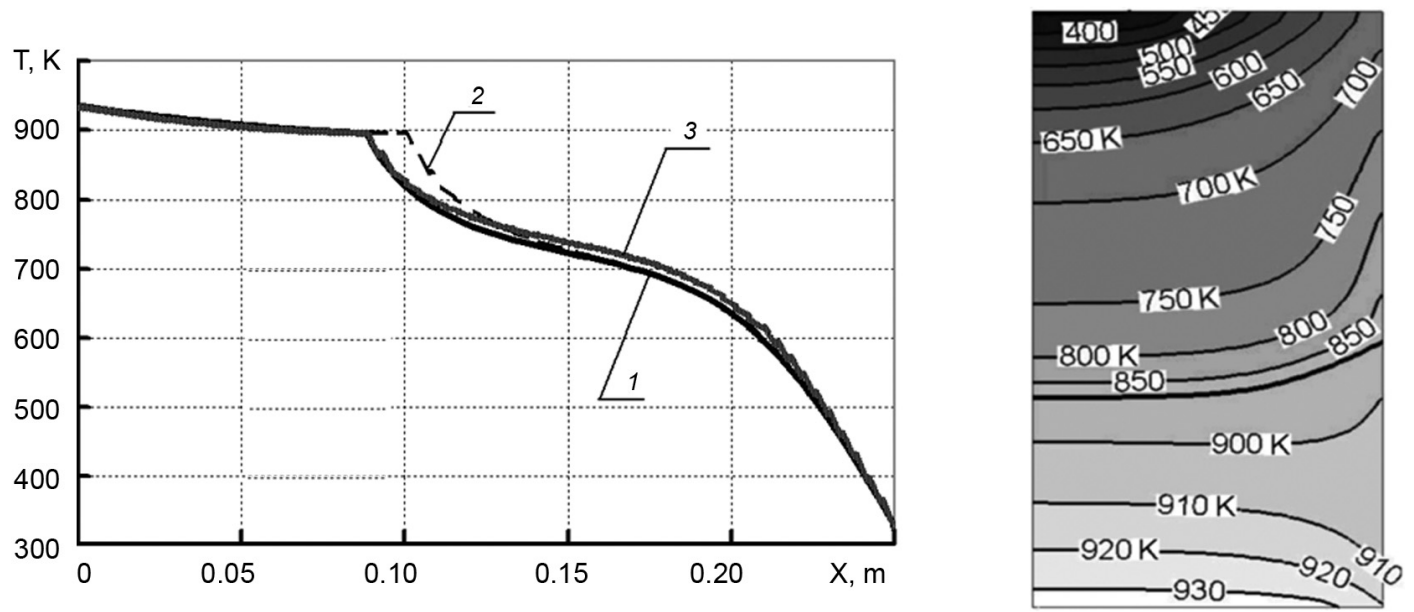

Fig. 11. Temperature distribution along the symmetry axis (left) and entirely for the selective model (right) for the bottom-heating Csl system. 1 - selective absorptivity; 2 - gray absorptivity $1.1 \mathrm{~m}^{-1} ; 3-$ gray absorptivity $2 \mathrm{~m}^{-1}$.

performance. Presented numerical model allowed revealing the main tendencies of radiation-convective heat transfer in the semitransparent media with phase-change boundary. The role of radiation and convection heat transfer and their interaction were examined. These recommendations are to be used in simulation of the wide range of high-temperature installations, particularly for simplified account of these heat transfer mechanisms using the standard simulation software.

The presented model provides dynamic evolution of the crystal-melt interface in accordance with the current thermal conditions in the system. The model may also be used in conjugation with the global models of crystallization installations, when calculation results of the global model are used in the local detailed model of the crystalmelt system. For example, the temperature fields and/or heat fluxes around simplified representation of the crystal-melt system in the global model are set as the boundary conditions for the local model. The latter provides refinement of thermal conditions inside the most important domain, namely the crystal-melt system. These data may be subsequently used to precise conditions within the global model.

A number of calculations provided determination of the impact of internal and external factors on the thermal conditions and position of the interface. Different classes of optical materials and different growth methods are represented as such factors. Moreover, the model allows assessment of capabilities of the temperature control methods, e.g. those based on the radiation screening. Finally, several assumptions and simplification and their usable limits are evaluated, particularly the laminar model for the melt domain, effective melt conductivity and gray assumption for the selectively absorbing optical materials.

The results were also used for development of the complex heat transfer model of Csl growth furnace, including full geometry of setup but simplifying such phenomena as selectivity of the materials and dynamic evolution of the crystal-melt interface. The conducted simulation has confirmed and adjusted the experimental data obtained by Kolesnikov et al. [13] regarding the temperature evolution of control bottom heater of the furnace.

\section{References}

1. C.W.Lan, Chem. Engin. Sci., 59, 1437 (2004).

2. V.V.Kalayev, Yu.N.Makarov, V.S.Yuferev, A.I.Zhmakin, in: Crystal Growth Technology: From Fundamentals and Simulation to LargeScale Production, ed. by H.J.Scheel and P.Capper, New York, Wiley-VCH (2007).

3. M.Abrams, R.Viskanta, J.Heat Transfer, 96, 184 (1974).

4. R.Viskanta, E.E.Anderson, Adv. Heat Transfer, 11, 317 (1975).

5. Q.Xiao, J.J.Derby, J.Cryst. Growth, 128, 188 (1993).

6. A.Yeckel, J.J.Derby, J.Electron. Mater., 33, 1 (2004).

7. V.S.Yuferev, O.N.Budenkova, M.G.Vasiliev et al., J.Cryst. Growth, 253, 383 (2003).

8. A.Hayashi, M.Kobayashi, Ch.Jing et al., Int.J. Heat Mass Transfer, 47, 5501 (2004). 
9. Z.Galazka, H.Wilke, J.Cryst. Res. Techn., 35, 1263 (2000).

10. A.Voigt, C.Weichmann, J.Nitschkowski et al., J. Cryst. Research Technology, 37, 77 (2002).

11. I.Yu.Evstratov, V.V.Kalaev, A.I.Zhmakin et al., J.Crystal Growth, 230, 22 (2001).

12. V.V.Kalaev, A.I.Zhmakin, E.M.Smirnov, $J$. Turbulence, 3, 1 (2002).

13. A.V.Kolesnikov, V.I.Deshko, Yu.V.Lokhmanets, Functional Materials, 17, 483 (2010).

14. K.Lin, P.Dold, J.Cryst. Res. Technology, 36, 629 (2001).

15. A.Yeckel, J.J.Derby, Bulk Crystal Growth of Electronic, Optical and Optoelectronic Materials, New-York, Wiley (2005).

16. V.I.Deshko, V.D.Golyshev, A.Ya.Karvatskii et al., Functional Materials, 15, 90 (2008).
17. V.I.Deshko, A.Ya.Karvatskii, A.V.Lenkin, Yu.V.Lokhmanets, Functional Materials, 15, 229 (2008).

18. ANSYS FLUENT 12.0 Documentation (2009).

19. S.V.Bykova, V.D.Golyshev, M.A.Gonik et al., J. Cryst. Growth, 266, 247 (2004).

20. H.K.Versteeg, W.Malalasekera, An Introduction to Computational Fluid Dynamics: The Finite Volume Method, 2nd ed., Prentice Hall, Harlow, England (2007).

21. J.Y.Murthy, S.R.Mathur, A Finite Volume Method For Radiative Heat Transfer Using Unstructured Meshes, AIAA-98-0860 (1998).

22. S.A.Orszag, V.Yakhot, W.S.Flannery et al., in: Int. Conf. Near-Wall Turbulent Flows, Tempe, Arizona (1993). 